\title{
USE OF BETA-TRICALCIUM PHOSPHATE WITH BONE MARROW ASPIRATE AS A BONE GRAFT SUBSTITUTE IN POSTEROLATERAL LUMBAR FUSION
}

\author{
๑ Cengiz TUNCER ${ }^{1}$, ๑ Ömer POLAT ${ }^{1}$, ๑ Uygur ER ${ }^{2}$ \\ ${ }^{1}$ Düzce University Faculty of Medicine, Department of Neurosurgery, Düzce, Turkey \\ 2Private Practice, Clinic of Neurosurgery, Ankara, Turkey
}

\begin{abstract}
Objective: Retrospective clinical study. This study aimed to determine the bony fusion rate of posterior lumbar fusion (PLF) involving betatricalcium phosphate (B-TCP) and bone marrow aspirate (BMA). Bone fusion remains the main component of primary surgical approach for several spinal disorders. Spine surgeons face the need to make crucial decisions regarding bone graft selection in each case.

Materials and Methods: The study included 33 patients (21 female and 12 male patients) who underwent posterior lumbar pedicle screw fixation and fusion using ß-TCP as a bone substitute. The mean patient age was 58.35 (range=35-81) years.

Results: The mean follow-up duration was 23.45 months. Solid bony fusion at the lateral side of the lumbar region between transverse processes was noted on radiography in 24 patients (72.7\%), bony bridging between adjacent transverse processes in 5 patients (15.2\%), and no new bone formation in the remaining 4 patients (12.1\%).

Conclusion: The bony fusion rate of PLF involving ß-TCP and BMA was relatively high at $72.7 \%$. B-TCP is an effective and appropriate material for PLF in the lumbar area when used with BMA, and approximately $10 \mathrm{~mL}$ of B-TCP per vertebral segment is sufficient.

Keywords: Bone graft substitute, fusion, lumbar, multi-segment posterolateral fusion, spine, beta-tricalcium phosphate
\end{abstract}

\section{INTRODUCTION}

Over the previous years, the number of posterior lumbar fusion (PLF) surgeries has gradually increased ${ }^{(11)}$. Spine surgeons face the need to make crucial decisions regarding bone graft selection in each case. The development of instrumentation materials and techniques has caused this expansion in the adoption of posterior lumbar surgeries, and global educational meetings and courses have helped to popularize these surgeries. In the previous decades, an autograft obtained from the iliac crest has been considered as the most desirable kind of bone substitute ${ }^{(10)}$. It provides osteogenic factors and a skeleton for healthy and strong bony fusion and is better than any other bone substitute. However, the high complication rate associated with harvesting an iliac crest graft has resulted in the development of alternative graft options. A good bone graft should exhibit strong biomechanics and should have biological properties, such as osteoinductivity and osteoconductivity. Additionally, it should be non-toxic (bioinert) and should be easy to sterilize. Ceramic carriers are derived from a process called "sintering," which uses high temperatures to extract individual crystals that are fused together at crystal grain boundaries ${ }^{(2)}$. These products are mainly synthetic and can provide an osteoconductive matrix ${ }^{(3,6)}$. Some ceramic substitutes provide scaffolds that are sufficient to protect the fusion area from loading forces, and they have all of these properties to some extent. Calcium phosphates, such as hydroxyapatite and betatricalcium phosphate ( $B-T C P)$, are the most preferable options for spinal fusion. This retrospective study aimed to determine the bony fusion rate of PLF involving B-TCP and bone marrow aspirate (BMA).

\section{MATERIALS AND METHODS}

\section{Patients}

This retrospective study included 33 consecutive adult patients (21 female and 12 male) who had undergone decompression and posterior lumbar pedicle screw fixation and fusion using (Suprabone ${ }^{\mathrm{TM}}$, BMT Calsis Co., Ankara, TURKEY) as a bone substitute. The mean patient age was 58.35 years (range $=35-81$ 
years). Patients with metabolic bone diseases, severe uncontrolled diabetes, renal failure, and neoplastic diseases were excluded from the study. Additionally, patients who had undergone previous lumbar surgery for any reason were also excluded. A total of 72 vertebral segments were instrumented and fused in 33 patients (2.2 segments per patient).

\section{Study Approval}

This study was approved by the local ethics committee, and the need for informed consent was waived owing to the retrospective nature of the study.

\section{Surgical Technique}

Under general anesthesia and in the prone position, the target vertebral levels were identified using an image intensifier. Surgical exposure was performed for the facet joints, and the transverse processes could be seen. Decompression of the spinal canal and relevant nerve roots was performed via laminectomy and foraminotomy. After pedicle screw fixation, decortication was completed using a high-speed drill or an osteotome for all the target levels. Bony fusion was performed with B-TCP and BMA. Approximately $10 \mathrm{~mL}$ of $B$-TCP was used for each vertebral segment. Bone substitutes were placed laterally over the transverse processes bilaterally.

\section{Bone Fusion Criteria}

After a reasonable follow-up period, bone fusion was evaluated on plain posteroanterior lumbar radiography. Bone fusion was classified into the following three stages: stage 0 , no new visible bone formation (Figure 1); stage 1, incomplete bridging across adjacent transverse processes (Figure 2); and stage 2, solid fusion (Figure 3).

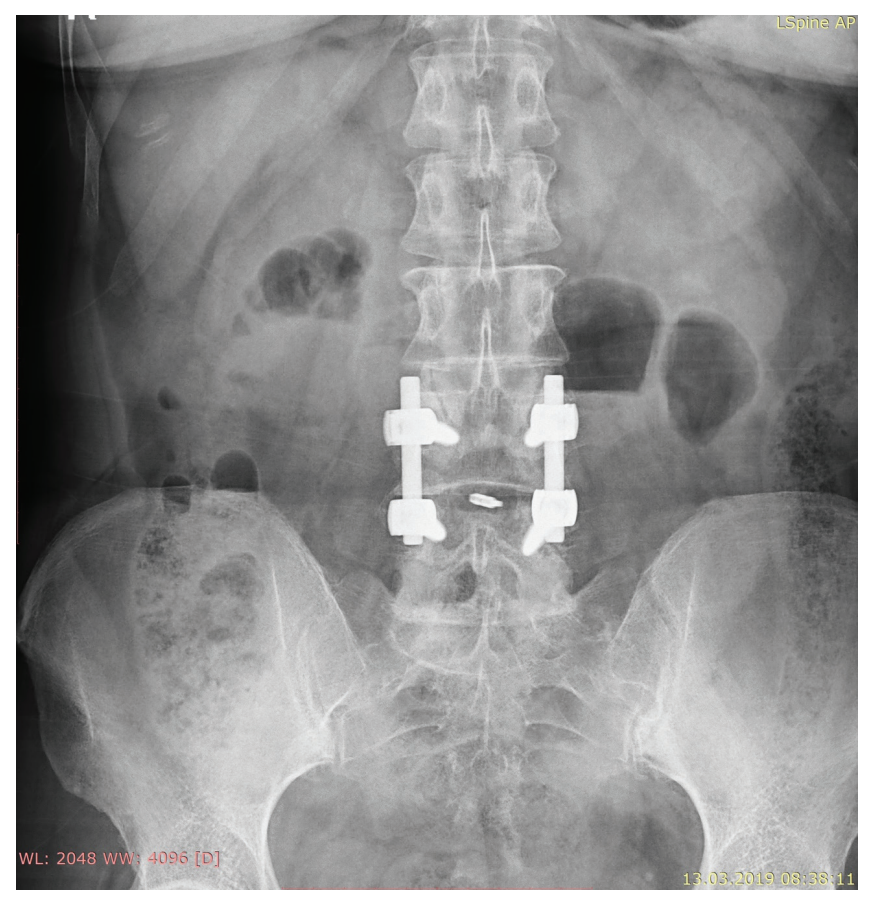

Figure 1. Stage 0 fusion. There is no new bone formation at the lateral side of the lumbar vertebrae on the posteroanterior lumbar roentgenography

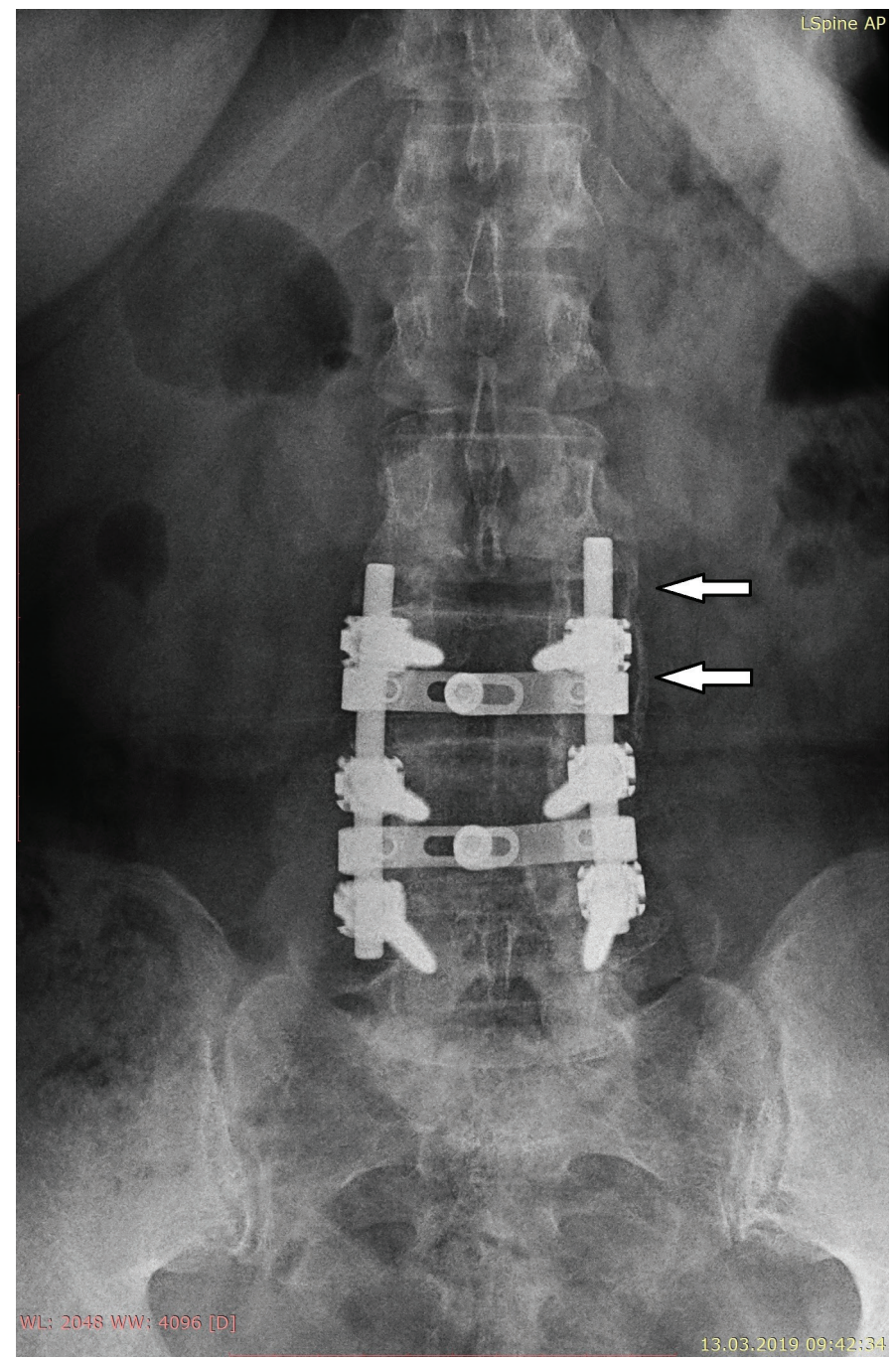

Figure 2. Stage 1 fusion. Some bony bridging is noted between transverse processes (white arrows) on the posteroanterior lumbar roentgenography, indicating incomplete fusion

\section{RESULTS}

The study included 33 patients. The fusion levels, number of fused vertebral segments, and preoperative diagnoses are presented in Table 1. The mean follow-up period was 23.45 months (range $=6-86$ months). Solid bony fusion at the lateral side of the lumbar region between transverse processes (stage 2 fusion) was noted on radiography in 24 patients (72.7\%), bony bridging between adjacent transverse processes (stage 1 fusion) in 5 patients (15.2\%), and no new bone formation (stage 0 fusion) in the remaining 4 patients (12.1\%). The mean followup durations of stage 0,1 , and 2 patients were $8.5,11$, and 28.22 months, respectively. The follow-up duration was shorter in patients with stage 0 and 1 fusion and longer in patients with stage 2 fusion than in the overall study population. There was no difference in fusion stage between male and female patients. 


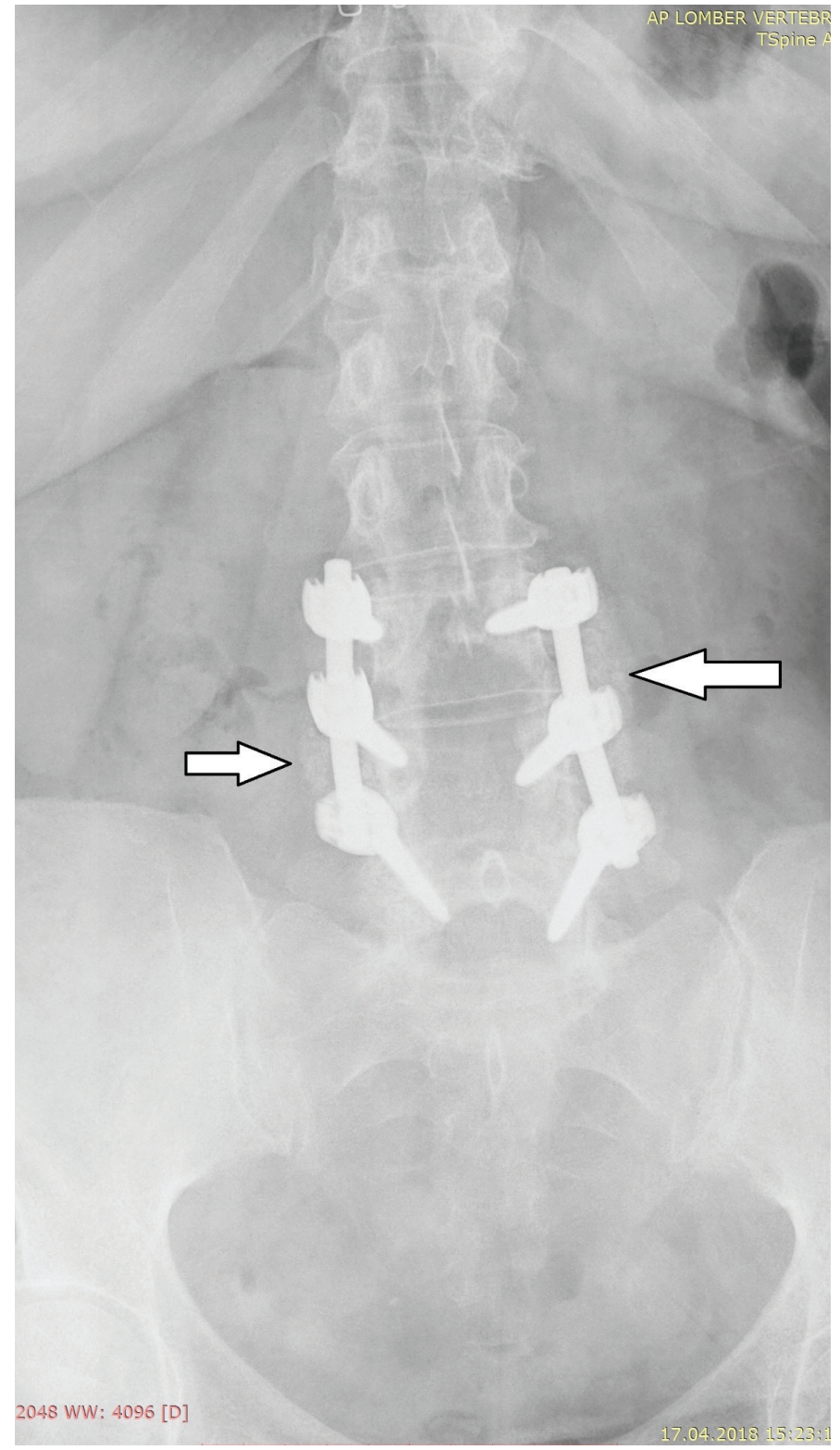

Figure 3. Stage 2 fusion. Solid fusion is noted between transverse processes (white arrows) on the posteroanterior lumbar roentgenography

Table 1. Patient demographics, preoperative diagnoses, and fusion levels

\begin{tabular}{lccccccc|}
\hline $\begin{array}{l}\text { Preoperative } \\
\text { diagnoses }\end{array}$ & M & F & T & \multicolumn{2}{l}{ Surgery of fused segments } \\
\hline & 11 & 18 & 29 & & 10 & 19 \\
\hline $\begin{array}{l}\text { Lumbar } \\
\text { stenosis }\end{array}$ & - & 2 & 2 & 2 & - & - \\
\hline $\begin{array}{l}\text { Lumbar } \\
\text { listhesis }\end{array}$ & 1 & 1 & 2 & 2 & - & - \\
\hline $\begin{array}{l}\text { Lumbar } \\
\text { instability }\end{array}$ & 12 & 21 & 33 & 4 & 10 & 19 \\
\hline Total & & & & & & \\
\hline
\end{tabular}

M: Male, F: Female, T: Total

\section{DISCUSSION}

Although the optimal treatment for degenerative lumbar diseases remains controversial ${ }^{(12)}$, bone fusion is the goal of many treatment approaches for various lumbar pathologies that especially need decompression ${ }^{(3,5)}$. Fusion may be posterolateral, anterior, or both. Posterolateral fusion can easily be performed after decompression in the same surgical step, and it is therefore the most widespread approach. Bone graft substitutes have been routinely used in spinal fusion for decades, and surgeons are faced with critical decisions regarding bone graft selection ${ }^{(4)}$. The formation of solid bone, duration of new bone formation, and stability of the lumbar region are important issues in the bone fusion process. Additionally, the physical and chemical properties of the bone substitute material and the amount of material are also important for efficient and adequate fusion. B-TCP is a popular ceramic and an osteoconductive synthetic bone substitute with a mineral structure similar to that of bone. Additionally, it is extremely porous and has a resorption time between 12 and 24 months $^{(9)}$. According to a meta-analysis, it has a fusion rate of $87 \%$ in PLF when used with an osteoinductive autologous source of cells obtained from either the vertebral body or iliac crest $^{(4)}$. In the present study, the autologous cell source was BMA obtained from the vertebra. BMA provides an effective amount of osteoprogenitor cells and critical growth factors that aid in cell differentiation, leading to bone healing. In vitro studies have confirmed a high colony-forming unit count in BMA obtained from the vertebral body ${ }^{(8)}$. In the present study, solid posterolateral fusion was achieved in $74.1 \%$ of patients and incomplete fusion was achieved in $12.9 \%$ of patients, indicating the competence of $B$-TCP for PLF. In most cases, $10 \mathrm{~mL}$ of $ß-T C P$ per vertebral segment provided sufficient bone fusion. The mean follow-up duration of the present study was considered to be satisfactory. In the relevant literature, the mean followup duration for efficient bone formation has been reported to be 18-20 months ${ }^{(1,7)}$. With regard to B-TCP, meta-analyses and some studies have reported fusion rates of $85 \%-100 \%$ in the lumbar area ${ }^{(1,4)}$. The fusion rate in the present study was lower than these rates. There are several possible reasons for this finding, including differences in the bone substitute amount, follow-up duration, and evaluation method. The follow-up duration was longer in the present study than in the previous studies. Additionally, the short follow-up duration for patients who showed no new bone formation might explain the finding. The follow-up duration of patients who showed incomplete fusion was longer than that of patients who showed no new bone formation but was shorter than that of patients who showed solid fusion, supporting this opinion. However, it should be noted that some patients showed solid fusion in 6 months. The previous studies did not mention the bone substitute amount, and thus, it was not possible to compare the bone substitute amount between our study and the previous studies. 
The evaluation method is extremely important, and computed tomography might be superior to direct roentgenography for evaluating new bone formation.

\section{Study Limitations}

The study population was not large enough to reach a definitive conclusion. Additionally, the pathologies and clinical diagnoses of the patients were not homogenous. Moreover, the age range was wide. Age is an important factor for fusion, and thus, the age range should be narrow. Finally, there was no comparison with an allograft. Such a comparison is necessary to demonstrate efficacy.

\section{CONCLUSION}

The bony fusion rate of PLF involving B-TCP and BMA was relatively high at $72.7 \%$. Bone graft substitutes and extenders are used and developed on a daily basis in spinal surgery. Surgeons might decide to select bone substitute material for spinal fusion according to the results of independent studies. $B$-TCP is an effective and appropriate material for PLF in the lumbar region when used with BMA, and approximately $10 \mathrm{~mL}$ of $B$-TCP per vertebral segment is sufficient.

\section{Ethics}

Ethics Committee Approval: Retrospective study.

Informed Consent: The need for informed consent was waived owing to the retrospective nature of the study.

Peer-review: Internally peer-reviewed.

\section{Authorship Contributions}

Surgical and Medical Practices: U.E., Concept: C.T., U.E., Design: Ö.P., U.E., Data Collection or Processing: C.T., Ö.P., Analysis or Interpretation: U.E., Li terature Search: C.T., Ö.P., Writing: U.E.

Conflict of Interest: No conflict of interest was declared by the authors.

Financial Disclosure: From BMT Calsis Co., or any other third party establishments.

\section{REFERENCES}

1. Dai LY, Jiang LS. Single-level instrumented posterolateral fusion of lumbar spine with beta-tricalcium phosphate versus autograft: a prospective, randomized study with 3-year follow-up. Spine (Phila Pa 1976) 2008;33:1299-304.

2. Finkemeier CG. Bone-grafting and bone-graft substitutes. J Bone Joint Surg Am 2002;84-A:454-64.

3. Guigui P, Ferrero E. Surgical treatment of degenerative spondylolisthesis. Orthop Traumatol Surg Res 2017;103:S11-S20.

4. Hsu WK, Nickoli MS, Wang JC, Lieberman JR, An HS, Yoon ST, et al. Improving the clinical evidence of bone graft substitute technology in lumbar spine surgery. Global Spine J 2012;2:239-48.

5. Lee CS, Hwang CJ, Lee DH, Kim YT, Lee HS. Fusion rates of instrumentedlLumbar spinal arthrodesis according to surgical approach: A systematic review of randomized trials. Clin Orthop Surg 201;3:39-47.

6. Lindley EM, Barton C, Blount T, Burger EL, Cain CM, Seim HB, et al. An analysis of spine fusion outcomes in sheep pre-clinical models. Eur Spine J 2017;26:228-39.

7. Lerner T, Bullmann V, Schulte TL, Schneider M, Liljenqvist U. A level-1 pilot study to evaluate of ultraporous beta-tricalcium phosphate as a graft extender in the posterior correction of adolescent idiopathic scoliosis. Eur Spine J 2009;18:170-9.

8. McLain R F, Fleming J E, Boehm C A, Muschler G F. Aspiration of osteoprogenitor cells for augmenting spinal fusion: comparison of progenitor cell concentrations from the vertebral body and iliac crest. J Bone Joint Surg Am 2005;87:2655-61.

9. Park JJ, Hershman SH, Kim YH. Updates in the use of bone grafts in the lumbar spine. Bulletin of the Hospital for Joint Diseases 2013;71:39-48.

10. Thaler M, Lechner R, Gstöttner M, Kobel C, Bach C. The use of beta-tricalcium phosphate and bone marrow aspirate as a bone graft substitute in posterior lumbar interbody fusion. Eur Spine J 2013;22:1173-82.

11. Weinstein JN, Lurie JD, Olson PR, Bronner KK, Fisher ES. United States' trends and regional variations in lumbar spine surgery. Spine 2006;31:2707-14.

12. Zhang $Q$, Yuan Z, Zhou M, Liu H, Xu Y, Ren Y. A comparison of posterior lumbar interbody fusion and transforaminal lumbar interbody fusion: a literature review and meta-analysis. BMC Musculoskelet Disord 2014;15:367-75. 